\title{
Optimal timing of cholecystectomy after percutaneous gallbladder drainage for severe cholecystitis
}

\author{
Koetsu Inoue ${ }^{1 *}$ (D), Tatsuya Ueno', Orie Nishina', Daisuke Douchi', Kentaro Shima', Shinji Goto',
} Michinaga Takahashi ${ }^{1}$, Chikashi Shibata ${ }^{2}$ and Hiroo Naito ${ }^{1}$

\begin{abstract}
Background: The Tokyo guideline for acute cholecystitis recommended percutaneous transhepatic gallbladder drainage followed by cholecystectomy for severe acute cholecystitis, but the optimal timing for the subsequent cholecystectomy remains controversial.
\end{abstract}

Methods: Sixty-seven patients who underwent either laparoscopic or open cholecystectomy after percutaneous transhepatic gallbladder drainage for severe acute cholecystitis were enrolled and divided into difficult cholecystectomy (group A) and non-difficult cholecystectomy (group B). Patients who had one of these conditions were placed in group A: 1) conversion from laparoscopic to open cholecystectomy; 2) subtotal cholecystectomy and/or mucoclasis; 3) necrotizing cholecystitis or pericholecystic abscess formation; 4) tight adhesions around the gallbladder neck; and 5) unsuccessfully treated using PTGBD. Preoperative characteristics and postoperative outcomes were analyzed.

Results: The interval between percutaneous transhepatic gallbladder drainage and cholecystectomy in Group B was longer than that in Group A (631 h vs. $325 \mathrm{~h} ; p=0.031$ ). Postoperative complications occurred more frequently when the interval was less than $216 \mathrm{~h}$ compared to when it was more than $216 \mathrm{~h}$ ( $35.7 \mathrm{vs.} .7 .6 \% ; p=0.006$ ).

Conclusions: Cholecystectomy for severe acute cholecystitis was technically difficult when performed within $216 \mathrm{~h}$ after percutaneous transhepatic gallbladder drainage.

Keywords: Cholecystitis, Percutaneous transhepatic gallbladder drainage, Cholecystectomy

\section{Background}

Acute cholecystitis (AC) is a common disease for which laparoscopic cholecystectomy (LC) has become the standard treatment [1]. However, in patients with severe $\mathrm{AC}$, the rate of complications such as bile leak, common bile duct injury, and bowel injury is high after LC [2], suggesting an association between severity of inflammation and difficulty of LC. Therefore, evaluation of the severity of $\mathrm{AC}$ is important in determining the appropriate treatment.

The Tokyo Guidelines in 2007 was issued as the first international guidelines for the diagnosis and treatment

\footnotetext{
* Correspondence: koetsu0303@surg1.med.tohoku.ac.jp

'Department of surgery, South Miyagi Medical Center, 38-1 Aza-nishi,

Ogawara, Shibata-gun, Miyagi 989-1253, Japan

Full list of author information is available at the end of the article
}

of $\mathrm{AC}$ and has been recently revised as the Tokyo Guidelines 2013 (TG13) [3, 4]. The TG13 suggested that the criteria for AC should be based on clinical symptoms, physical examination, blood tests, and imaging findings and classified $\mathrm{AC}$ into three grades of inflammation: mild (grade I), moderate (grade II), and severe (grade III) (Table 1). The TG13 also recommended appropriate therapy depending on the grade of AC. Grade I patients are candidates for immediate LC; grade II patients could undergo either LC or percutaneous transhepatic gallbladder drainage (PTGBD); and grade III patients are strongly recommended to undergo immediate PTGBD.

In the early 1980s, Radder introduced the procedure of PTGBD to immediately improve the symptoms of $\mathrm{AC}$ [5]. In some patients who undergo PTGBD and 
Table 1 Severity classification of acute cholecystitis by the Tokyo guidelines 2013

\begin{tabular}{|c|c|}
\hline Grade & Definition \\
\hline \multirow[t]{2}{*}{ I (Mild) } & Acute cholecystitis that does not meet the criteria for grade III or grade II cholecystitis \\
\hline & $\begin{array}{l}\text { Acute cholecystitis in a healthy patient with no organ dysfunction. Inflammatory changes in the gallbladder are mild, making } \\
\text { cholecystectomy a safe and low-risk procedure. }\end{array}$ \\
\hline \multirow[t]{5}{*}{ II (Moderate) } & Grade II acute cholecystitis is associated with any one of the following conditions \\
\hline & 1 Elevated white blood cell count $\left(>18,000 / \mathrm{mm}^{3}\right)$ \\
\hline & Palpable tender mass in the right upper abdominal quadrant \\
\hline & Duration of complaints $>72 \mathrm{~h}$ \\
\hline & $\begin{array}{l}\text { Marked local inflammation (gangrenous cholecystitis, pericholecystic abscess, hepatic abscess, biliary peritonitis, and } \\
\text { emphysematous cholecystitis) }\end{array}$ \\
\hline \multirow[t]{7}{*}{ III (Severe) } & Grade III acute cholecystitis associated with dysfunction of any one of the following organs/systems \\
\hline & $\begin{array}{l}1 \text { Cardiovascular dysfunction defined as hypotension requiring treatment with dopamine } \geq 5 \mu \mathrm{g} / \mathrm{kg} \text { per min or } \\
\text { any dose of norepinephrine }\end{array}$ \\
\hline & Neurologic dysfunction defined as decreased level of consciousness \\
\hline & Respiratory dysfunction defined as a $\mathrm{PaO} 2 / \mathrm{FiO} 2$ ratio $<300$ \\
\hline & Renal dysfunction defined as oliguria or creatinine $>2.0 \mathrm{mg} / \mathrm{dl}$ \\
\hline & Hepatic dysfunction defined as PT-INR > 1.5 \\
\hline & Hematologic dysfunction defined as platelet count $<100,000 / \mathrm{mm}^{3}$ \\
\hline
\end{tabular}

subsequent LC, technical difficulties and postoperative complications associated with severe fibrosis and gallbladder adhesion may be encountered [6]. Therefore, it is very important to determine the optimal timing of cholecystectomy after PTGBD; however, this is still controversial [4].

The aim of this study was to assess the effect of the interval between PTGBD and cholecystectomy on the technical difficulty of cholecystectomy and postoperative complications. We also aimed to determine the optimal timing of cholecystectomy after PTGBD.

\section{Methods}

The medical records of the 77 study patients who underwent either laparoscopic or open cholecystectomy after PTGBD for AC between 2002 and 2015 were retrospectively reviewed (Fig. 1). Ten patients who met one of the conditions below were excluded from this study: 1) hemorrhage associated with liver cirrhosis, 2) relapsed cholecystitis after PTGBD tube removal, and 3) need for procedures other than cholecystectomy. At least one board-certified surgeon of the Japan Surgical Society participated in all surgeries.

Since there was no quantitative evaluation for the difficulty of cholecystectomy, we employed objective and subjective criteria in this study. Difficult cholecystectomy was defined as the presence of either one of these conditions: 1) conversion from laparoscopic to open cholecystectomy; 2) atypical cholecystectomy, such as subtotal cholecystectomy and/or mucoclasis; 3) necrotizing cholecystitis or pericholecystic abscess formation; 4) tight adhesions around the gallbladder neck; and 5) a patient unsuccessfully treated using PTGBD. In grade I and II cholecystites, timing of surgery following PTGBD was decided by each surgeon. In grade III cholecystitis, surgery was performed after recovery of patient from organ dysfunction. Decision of conversion during surgery depended on each surgeon. There were no definite criteria for performing either open cholecystectomy or laparoscopic cholecystectomy.

Necrotizing cholecystitis was confirmed by intraoperative and pathologic findings. The remaining 67 patients were divided into two groups according to the criteria mentioned above: the difficult cholecystectomy group (group A, $n=35$ ) and the non-difficult cholecystectomy group (group $\mathrm{B}, n=32$ ). Preoperative characteristics and postoperative outcomes were analyzed. Detailed data of patient characteristics used in this study was shown in Additional file 1.

Data are shown as mean \pm standard error mean (SEM). Categorical variables were analyzed by Chisquare test, whereas continuous data were analyzed by either two-tailed Student's t test or Wilcoxon test, according to the result of the Shapiro-Wilk test. Statistical significance was defined as $P<0.05$. The optimal cut-off value was calculated using a receiver operating characteristic (ROC) curve and was defined as the number that indicated the highest sum of the sensitivity and specificity on the ROC curve. Statistical analysis was performed with JMP Pro 11 software (SAS Institute, Cary, NC, U.S.A). 


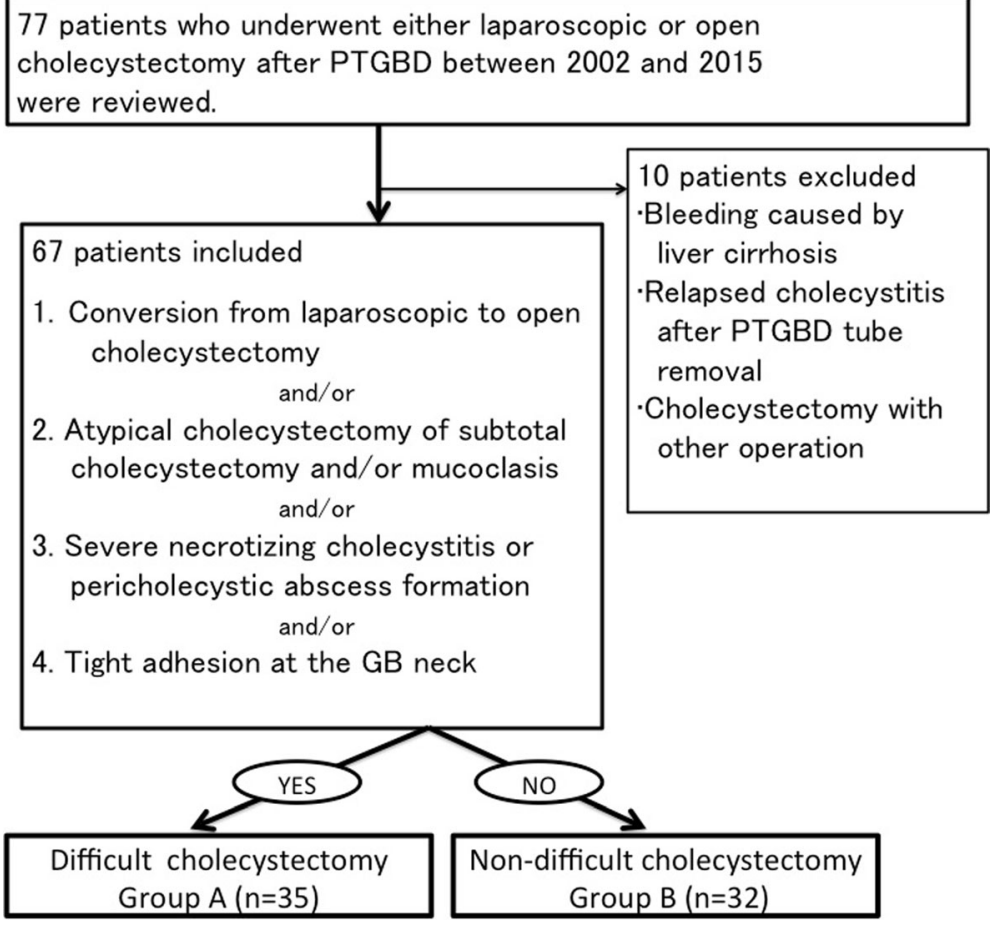

Fig. 1 Study flow chart. PTGBD: percutaneous transhepatic gallbladder drainage

\section{Results}

Among the 67 patients enrolled in this study, 41 $(61.2 \%)$ were men, and the median age was 75.0 years. The severity of AC was grade I in 13 cases (19.4\%), grade II in 42 cases $(62.7 \%)$, and grade III in 12 cases (17.9\%). There were 3 patients who were unsuccessfully treated using PTGBD (one patient: relapsed cholecystitis following PTGBD, 2 patients: bile peritonitis due to PTGBD), and rate of patients with unsuccessfully treated with PTGBD was $3.9 \%$. Patients enrolled in this study, did not have troubles associated with PTGBD tube. Nine patients needed conversion from LC to open cholecystectomy, whereas 45 patients underwent LC. The reasons for conversion were as follows: 1) inadequate exposure of Calot's triangle due to severe adhesion and inflammation in 8 cases and 2) accidental cystic duct injury in one case. In 13 patients, open cholecystectomy was selected at the beginning of the surgery. The reasons for selecting open cholecystectomy were as follows: 1) history of upper abdominal surgery in 6 cases, 2) Mirrizi syndrome at admission in 3 cases, 3) acute pancreatitis at admission in 2 cases, and 5) severe wall thickness in 2 cases.

The interval between PTGBD and cholecystectomy ranged from 2 to $4584 \mathrm{~h}$, with the median at $360 \mathrm{~h}$. Only seven cases had an interval between procedures of within $72 \mathrm{~h}$. The detailed patient characteristics are shown in Table 2. The interval between PTGBD and
Table 2 Comparison of patient clinical characteristics according to the difficulty of cholecystitis

\begin{tabular}{|c|c|c|c|}
\hline \multirow[t]{2}{*}{ Variable } & \multirow{2}{*}{$\begin{array}{l}\text { Group A } \\
(n=35)\end{array}$} & \multirow{2}{*}{$\begin{array}{l}\text { Group B } \\
(n=32)\end{array}$} & \multirow[t]{2}{*}{$P$ Value } \\
\hline & & & \\
\hline Age, years & $69.3 \pm 2.1$ & $73.3 \pm 2.2$ & 0.192 \\
\hline Male sex, n (\%) & $22(62.9)$ & $19(59.4)$ & 0.770 \\
\hline BMI & $24.3 \pm 0.70$ & $22.3 \pm 0.73$ & 0.053 \\
\hline $\begin{array}{l}\text { Interval between onset } \\
\text { and PTGBD, hours }\end{array}$ & $77.5 \pm 12.8$ & $78.0 \pm 13.4$ & 0.978 \\
\hline $\begin{array}{l}\text { Interval between PTGBD and } \\
\text { cholecystectomy, hours }\end{array}$ & $325.0 \pm 95.6$ & $631.0 \pm 99.9$ & 0.031 \\
\hline Fever on admission, $\mathrm{n}(\%)$ & & & 0.609 \\
\hline No & $25(71.4)$ & $21(65.6)$ & \\
\hline Yes & $10(28.6)$ & $11(34.4)$ & \\
\hline \multicolumn{2}{|c|}{ Abdominal pain on admission, $\mathrm{n}(\%)$} & & 0.196 \\
\hline No & $4(11.4)$ & $1(3.1)$ & \\
\hline Yes & 31 (88.6) & $31(96.9)$ & \\
\hline \multicolumn{4}{|l|}{ Tokyo Guidelines 2013} \\
\hline Grade I & $5(14.3)$ & $8(25.0)$ & 0.268 \\
\hline Grade II & $22(62.9)$ & $20(62.5)$ & 0.976 \\
\hline Grade III & $8(22.9)$ & $4(12.5)$ & 0.269 \\
\hline Hypertension & $19(54.3)$ & $12(37.5)$ & 0.169 \\
\hline Diabetes mellitus & $8(22.9)$ & $3(9.4)$ & 0.137 \\
\hline
\end{tabular}


cholecystectomy in Group B was significantly longer than that in Group A $(325 \pm 95.6$ h vs. $631 \pm 99.9$ h; $p=0.031$ ), whereas the interval between symptom onset and PTGBD did not differ between the two groups $(77.5 \pm 12.8 \mathrm{~h}$ vs. $78.0 \pm 13.4 \mathrm{~h} ; p=0.978)$. All other parameters did not differ between the two groups. Table 3 shows that AST and $\gamma$-GTP were lower in group A than in group B (AST: $76.3 \pm 38.6 \mathrm{IU} / \mathrm{L}$ vs. $196 \pm 40.4 \mathrm{IU} / \mathrm{L} ; p=0.036$ and $\gamma-\mathrm{GTP}: 95.3 \pm 36.6 \mathrm{IU} /$ $\mathrm{L}$ vs. $240 \pm 38.3 \mathrm{IU} / \mathrm{L} ; p=0.008$ ), but all other data including WBC and CRP did not differ between groups. Perioperative characteristics are shown in Table 4. Operating time $(146 \pm 5.8 \mathrm{~min}$ vs. $97.3 \pm 6.1 \mathrm{~min}$; $p<.0001)$ and blood loss $(180 \pm 32.1 \mathrm{~mL}$ vs. $28.8 \pm 33.6 \mathrm{~mL} ; p=0.0017)$ were significantly greater in Group A than in Group B. Distribution of surgical procedures in the 67 patients was as follows; Laparoscopic cholecystectomy: Group A, 21 cases (60.0\%) and Group B, 24 cases (75.5\%); Open cholecystectomy: Group A, 5 cases (14.3\%) and Group B, 8 cases (25.0\%); and Open conversion: Group A, 9 cases (25.7\%) and Group B, 0 cases (0\%). The rate of open cholecystectomy did not differ between the two groups $(p=0.268)$.

ROC curve analysis yielded a value of $216 \mathrm{~h}$ as the optimal cut-off interval between PTGBD and cholecystectomy, in relation to the difficulty of cholecystectomy (Fig. 2). Using this cut-off value, patients were divided into the short interval (SI) $(n=14)$ and the long interval (LI) $(n=53)$ groups. The perioperative outcomes are shown in Table 5 . The number of patients who underwent difficult cholecystectomy was significantly greater in the SI group than in the LI group ( 85.7 vs. $43.4 \% ; p=0.005$ ). Compared with the LI group, the SI group had significantly longer operating

Table 3 Comparison of laboratory data on admission according to the difficulty of cholecystitis

\begin{tabular}{llll}
\hline Variable & $\begin{array}{l}\text { Group A } \\
(n=35)\end{array}$ & $\begin{array}{l}\text { Group B } \\
(n=32)\end{array}$ & $P$ Value \\
\hline White blood cells, $10^{3} / \mu \mathrm{L}$ & $13.0 \pm 0.99$ & $14.6 \pm 1.04$ & 0.275 \\
Hemoglobin, g/dL & $13.2 \pm 0.38$ & $13.6 \pm 0.40$ & 0.474 \\
Platelets, $10^{3} / \mu \mathrm{L}$ & $181 \pm 14.0$ & $197 \pm 14.6$ & 0.429 \\
CRP, $\mathrm{mg} / \mathrm{dL}$ & $13.2 \pm 1.85$ & $10.4 \pm 1.93$ & 0.284 \\
Total bilirubin, mg/dL & $1.6 \pm 0.34$ & $2.5 \pm 0.35$ & 0.053 \\
AST, IU/L & $76.3 \pm 38.6$ & $196 \pm 40.4$ & 0.036 \\
ALT, IU/L & $82.7 \pm 24.4$ & $121 \pm 25.6$ & 0.283 \\
ALP, IU/L & $327 \pm 38.8$ & $439 \pm 40.6$ & 0.052 \\
Y-GTP, IU/L & $95.3 \pm 36.6$ & $240 \pm 38.3$ & 0.008 \\
\hline
\end{tabular}

CRP C-reactive protein, AST Aspartate aminotransferase, ALT Alanine aminotransferase ALP Alkaline phosphatase, $\gamma$-GTP Gamma-glutamyl transpeptidase Continuous variables are presented as mean \pm SEM
Table 4 Comparison of perioperative characteristics according to the difficulty of cholecystitis

\begin{tabular}{llll}
\hline Variable & $\begin{array}{l}\text { Group A } \\
(n=35)\end{array}$ & $\begin{array}{l}\text { Group B } \\
(n=32)\end{array}$ & P Value \\
\hline Operating time, min & $146 \pm 5.8$ & $97.3 \pm 6.1$ & $<0.0001$ \\
Blood loss, mL & $180 \pm 32.1$ & $28.8 \pm 33.6$ & 0.0017 \\
Laparoscopic cholecystectomy, n (\%) & $21(60.0)$ & $24(75.0)$ & 0.192 \\
Open cholecystectomy, n (\%) & $5(14.3)$ & $8(25.0)$ & 0.268 \\
Open conversion, n (\%) & $9(25.7)$ & $0(0)$ & 0.002 \\
$\begin{array}{l}\text { Subtotal cholecystectomy and/or } \\
\text { mucoclasis, n (\%) }\end{array}$ & $25(71.4)$ & $0(0)$ & $<0.0001$ \\
Necrosis and/or abscess, n (\%) & $24(68.6)$ & $0(0)$ & $<0.0001$ \\
$\begin{array}{l}\text { Tight adhesion at the gallbladder } \\
\text { neck, n (\%) }\end{array}$ & $20(57.1)$ & $0(0)$ & $<0.0001$ \\
Gallbladder stone, n (\%) & $30(85.7)$ & $28(87.5)$ & 0.831 \\
\hline
\end{tabular}

Continuous variables are presented as mean \pm SEM

time (143 \pm 10.9 min vs. $117 \pm 5.6 \mathrm{~min} ; p=0.05)$; higher rates of necrosis and/or abscess formation (66.7 vs. $30.2 \% ; p=0.016)$ and adhesions around the gallbladder neck (50.0 vs. $22.6 \% ; p=0.043$ ); and higher incidence of postoperative complications, except surgical site infection ( 35.7 vs. $7.6 \% ; p=0.006)$. In particular, intraabdominal abscess developed more frequently in the SI group than in the LI group (21.4 vs. $0 \%$; $p=0.006)$. Duration of postoperative hospital stay did not differ between the two groups (SI group vs. LI group, $10.6 \pm 1.6$ days vs. $8.6 \pm 0.81$ days; $p=0.269$ ).

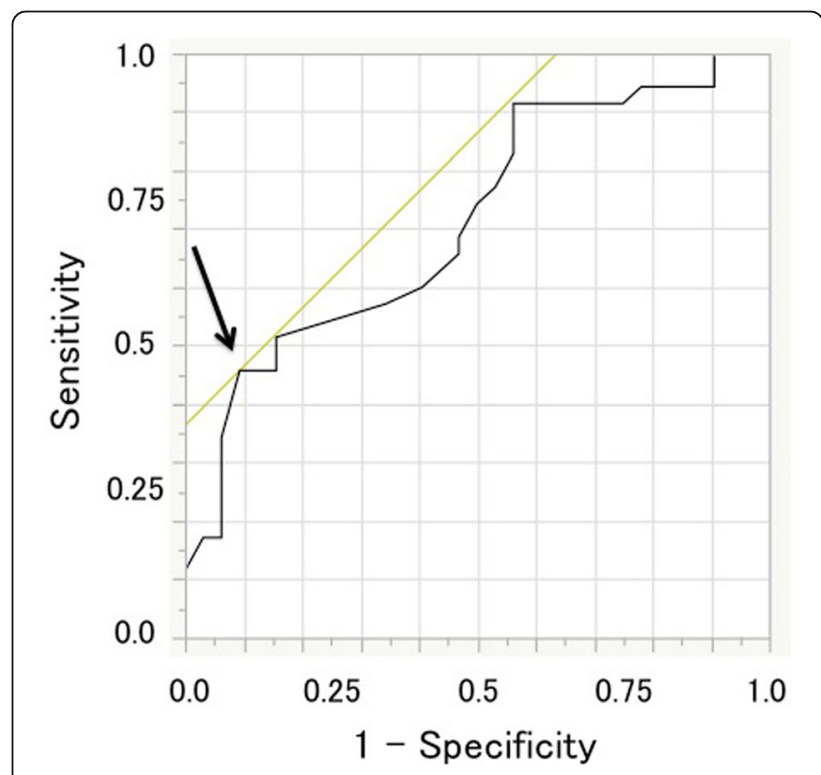

Fig. 2 ROC curve analysis of the interval between PTGBD and cholecystectomy and the technical difficulty of cholecystectomy. The area under the curve (AUC) is 0.712 . The cut-off value for the interval between PTGBD and cholecystectomy was calculated as $216 \mathrm{~h}$ 
Table 5 Comparison of perioperative characteristics and postoperative outcomes according to the interval between PTGBD and cholecystectomy

\begin{tabular}{llll}
\hline Variable & SI group & LI group & $P$ \\
& $n=14$ & $n=53$ & value \\
\hline Operating time, min & $143 \pm 10.9$ & $117 \pm 5.6$ & 0.041 \\
Blood loss, mL & $199 \pm 53.2$ & $83.8 \pm 27.3$ & 0.057 \\
Difficult cholecystectomy, n (\%) & $12(85.7)$ & $23(43.4)$ & 0.005 \\
Open conversion, n (\%) & $2(15.4)$ & $7(17.1)$ & 0.887 \\
Subtotal cholecystectomy and/or & $6(42.9)$ & $19(35.9)$ & 0.630 \\
mucoclasis, n (\%) & & & \\
Necrosis and/or abscess, n (\%) & $8(66.7)$ & $16(30.2)$ & 0.016 \\
Tight adhesion at the & $7(50.0)$ & $13(24.5)$ & 0.064 \\
gallbladder neck, n (\%) & & & \\
Postoperative complications except SSI, n (\%) & & 0.006 \\
$\quad$ Yes & $5(35.7)$ & $4(7.6)$ & \\
$\quad$ No & $9(64.3)$ & $49(92.4)$ & \\
Bile leak, n (\%) & $0(0)$ & $1(1.9)$ & 0.605 \\
Intraabdominal abscess, n (\%) & $3(21.4)$ & $0(0)$ & 0.0006 \\
Hematoma, n (\%) & $0(0)$ & $1(1.9)$ & 0.605 \\
Paralytic ileus, n (\%) & $1(7.1)$ & $2(3.8)$ & 0.588 \\
SSI, n (\%) & $1(7.1)$ & $3(5.7)$ & 0.835 \\
Postoperative hospital stay, days & $10.6 \pm 1.6$ & $8.6 \pm 0.81$ & 0.269 \\
\hline
\end{tabular}

SI group Short interval group, LI group Long interval group, SSI Surgical site infection

Continuous variables are presented as mean \pm SEM

\section{Discussion}

Recently, immediate LC has become standard treatment for $\mathrm{AC}[7,8]$. However, we sometimes experience difficulty during LC in AC patients with severe local inflammation; this can increase the rate of postoperative complications, such as bile leak, common bile duct injury, and bowel injury [2]. Furthermore, some investigators reported that the mortality rate was as high as $18-50 \%$ in elderly patients or those with severe comorbidities [9-11]. On the other hand, PTGBD is not a difficult procedure with a very low mortality rate [12]. Therefore, PTGBD has been performed as a safer substitute for cholecystectomy in such high-risk patients $[13,14]$. In this study, the rate of unsuccessful treatment using PTGBD was 3.9\%, and this result was acceptable compared with that in a previous report.

The TG13 has indicated the severity criteria for AC and its appropriate management, including PTGBD [3, 4], but the optimal timing for subsequent cholecystectomy after PTGBD was not mentioned. Chikamori et al. suggested that early LC following PTGBD was safe and effective [15]. On the other hand, Kim et al. suggested that delayed LC following PTGBD decreased the rates of open conversion and complications [16]. Yamada et al. suggested that the interval between PTGBD and cholecystectomy was not related to the amount of blood loss, operating time, and open conversion rate [17]. Therefore, the optimal timing for subsequent cholecystectomy after PTGBD is still controversial.

In this study, grade III AC patients who have organ dysfunction were enrolled. Although organ dysfunction seemed to negatively affect postoperative morbidity and mortality, all of grade III AC patients underwent operation after complete recover from organ dysfunction. Therefore, organ dysfunction did not affect postoperative outcomes.

At the beginning of this retrospective study, we assessed whether the interval between PTGBD and cholecystectomy was a risk factor for a difficult surgery. Based on our results, the interval between PTGBD and cholecystectomy was short in patients who underwent difficult cholecystectomy. Comparison of outcomes according to a cut-off interval of $216 \mathrm{~h}$ showed a significantly higher rate of postoperative complications, especially intraabdominal abscess, and prolonged operating time in the SI group than the LI group. These results indicated that cholecystectomy should be considered at least $216 \mathrm{~h}$ after PTGBD.

The proper definition of difficult cholecystectomy is crucial in this study. Although conversion to open cholecystectomy reflects a difficult LC, it could also depend on the surgeon's ability. In addition to conversion rate, objective and subjective criteria for difficult cholecystectomy were employed in this study based on results of previous reports. In particular, gallbladder inflammation was a risk factor for technical difficulty and conversion from LC to open cholecystectomy [18-20]. We believed that our criteria for difficult cholecystectomy were appropriate. Although BMI, CRP, and the interval between symptom onset and PTGBD were suggested as independent risk factors for difficult cholecystectomy $[17-21]$, these parameters did not differ between difficult and non-difficult cholecystectomy cases in this study.

In this study, early (within $72 \mathrm{~h}$ ) cholecystectomy following PTGBD was performed only in seven cases. Therefore, the usefulness of early cholecystectomy could not be adequately assessed. AC progresses from edematous cholecystitis through necrotizing cholecystitis to sub-acute cholecystitis in about 10 days, and edematous phase, which is a phase before proceeding tight adhesion, lasts for $72 \mathrm{~h}$ after symptom onset [22]. Necrotizing cholecystitis is also reported to be one of the risk factor for difficult LC [23, 24]. Thus, the Tokyo Guidelines recommend early LC. Accordingly, early cholecystectomy following PTGBD might reduce the incidence of postoperative complications. Some investigators reported rapid symptomatic improvement in more than $90 \%$ patients after cholecystectomy within 
24 to $72 \mathrm{~h}$ of PTGBD [25-27]. Indeed, some patients can safely undergo cholecystectomy soon after PTGBD. However, early LC following PTGBD for grade III cholecystitis seems challenging because of the accompanying severe organ dysfunction. Therefore, in patients who do not recover from organ dysfunction within $72 \mathrm{~h}$, we should not perform early LC.

One limitation of our study was inclusion of patients who underwent three different procedures (LC, conversion from LC to open cholecystectomy, and open cholecystectomy). Because operating time and blood loss could be confounded by these procedures, these two parameters had to be excluded from the criteria for difficult cholecystectomy. Surgical site infection was not included as a postoperative complication because of the same reason. The combination of three different procedures might also explain the same length of postoperative hospital stay among the patients, regardless of the interval between PTGBD and cholecystectomy.

In this study, the cut-off value of 216 -h interval between PTGBD and cholecystectomy was similar with that of a previous report (7 days) [16]. In general, when inflammation occurs, cytokines are produced and they cause fibrosis in 7 days [28]. It is also reported that further fibrosis does not occur after 7 days [29]. Therefore, there is a possibility that waiting for longer time leads to a safer cholecystectomy. However, there is no evidence regarding this, and further examination is required.

\section{Conclusions}

Cholecystectomy should be performed later than $216 \mathrm{~h}$ after PTGBD in patients with severe AC, although the possibility of a safe outcome of early LC within $72 \mathrm{~h}$ of PTGBD remains.

\section{Additional file}

Additional file 1: Detailed data of patient characteristics used in this study. 1: yes, 0: no. (XLSX $49 \mathrm{~kb}$ )

\section{Abbreviations}

AC: Acute cholecystitis; LC: Laparoscopic cholecystectomy; LI: Long interval; PTGBD: Percutaneous transhepatic gallbladder drainage; ROC: Receiver operating characteristic; SEM: Standard error mean; SI: Short interval; TG13: Tokyo Guidelines 2013

\section{Acknowledgements}

The authors would like to thank Enago (www.enago.jp) for the English language review.

\section{Availability of data and materials}

All data generated or analyzed during this study are included in supplementary information files.

\section{Funding}

Not applicable.

\section{Authors' contributions}

TU contributed to the conception and revised the work critically for important intellectual content and approved the version to be published and agreed to be accountable for all aspects of the work in ensuring that questions related to the accuracy and integrity of any part of the work were appropriately investigated and resolved. ON contributed to the design of the work and drafted the work and approved the version to be published and agreed to be accountable for all aspects of the work in ensuring that questions related to the accuracy. DD contributed to the design of the work and drafted the work and approved the version to be published and agreed to be accountable for all aspects of the work in ensuring that questions related to the accuracy. KS contributed to the design of the work and drafted the work and approved the version to be published and agreed to be accountable for all aspects of the work in ensuring that questions related to the accuracy. SG contributed to the design of the work and drafted the work and approved the version to be published and agreed to be accountable for all aspects of the work in ensuring that questions related to the accuracy. MT contributed to the design of the work and drafted the work and approved the version to be published and agreed to be accountable for all aspects of the work in ensuring that questions related to the accuracy. CS contributed to the conception and revised the work critically for important intellectual content and approved the version to be published and agreed to be accountable for all aspects of the work in ensuring that questions related to the accuracy. HN contributed to the conception and revised the work critically for important intellectual content and approved the version to be published and agreed to be accountable for all aspects of the work in ensuring that questions related to the accuracy and integrity of any part of the work were appropriately investigated and resolved.

\section{Competing interests}

The authors declare that they have no competing interests.

\section{Consent for publication}

Not applicable.

\section{Ethics approval and consent to participate}

This study protocol was reviewed and approved by the Ethics Committee of the South Miyagi Medical Center on November 8, 2016. Registration number: 16-12. Informed consent was waived by the Ethics Committee of the South Miyagi Medical Center.

\section{Publisher's Note}

Springer Nature remains neutral with regard to jurisdictional claims in published maps and institutional affiliations.

\section{Author details}

'Department of surgery, South Miyagi Medical Center, 38-1 Aza-nishi, Ogawara, Shibata-gun, Miyagi 989-1253, Japan. ${ }^{2}$ Division of Gastroenterological Surgery, Department of Surgery, Tohoku Medical and Pharmaceutical University Hospital, 1-12-1 Hukumuro, Miyagino-ku, Sendai, Miyagi, Japan.

Received: 17 January 2017 Accepted: 24 May 2017

Published online: 31 May 2017

\section{References}

1. Yamashita Y, Takada T, Strasberg SM, Pitt HA, Gouma DJ, Garden OJ, et al. TG13 surgical management of acute cholecystitis. J Hepatobiliary Pancreat Sci. 2013;20:89-96.

2. Lee SW, Yang SS, Chang CS, Yeh HJ. Impact of the Tokyo guidelines on the management of patients with acute calculous cholecystitis. J Gastroenterol Hepatol. 2009;24:1857-61.

3. Sekimoto M, Takada T, Kawarada Y, Nimura Y, Yoshida M, Mayumi T, Miura F, Wada K, Hirota M, Yamashita Y, Strasberg S. Need for criteria for the diagnosis and severity assessment of acute cholangitis and cholecystitis: Tokyo guidelines. J Hepato-Biliary-Pancreat Surg 2007;14:11-14

4. Yokoe M, Takada T, Strasberg SM, Solomkin JS, Mayumi T, Gomi H, et al. New diagnostic criteria and severity assessment of acute cholecystitis in revised Tokyo guidelines. J Hepatobiliary Pancreat Sci. 2012;19:578-85.

5. Radder RW. Ultrasonically guided percutaneous catheter drainage for gallbladder empyema. Diagn Imaging. 1980;49:330-3. 
6. Habib FA, Kolachalam RB, Khilnani R, Preventza O, Mittal VK. Role of laparoscopic cholecystectomy in the management of gangrenous cholecystitis. Am J Surg. 2001;181:71-5.

7. Borzellino G, Sauerland S, Minicozzi AM, Verlato G, Di Pietrantonj C, de Manzoni G, et al. Laparoscopic cholecystectomy for severe acute cholecystitis. A meta-analysis of results. Surg Endosc. 2008;22:8-15.

8. Gurusamy K, Samraj K, Gluud C, Wilson E, Davidson BR. Meta-analysis of randomized controlled trials on the safety and effectiveness of early versus delayed laparoscopic cholecystectomy for acute cholecystitis. Br J Surg. 2010;97:141-50.

9. Winbladh A, Gullstrand P, Svanvik J, Sandstrom P. Systematic review of cholecystostomy as a treatment option in acute cholecystitis. HPB (Oxford). 2009;11:183-93.

10. Morse BC, Smith JB, Lawdahl RB, Roettger RH. Management of acute cholecystitis in critically ill patients: contemporary role for cholecystostomy and subsequent cholecystectomy. Am Surg. 2010;76:708-12.

11. Laurila J, Syrjala H, Laurila PA, Saarnio J, Ala-Kokko TI. Acute acalculous cholecystitis in critically ill patients. Acta Anaesthesiol Scand. 2004;48:986-91.

12. Ito K, Fujita N, Noda Y, Kobayashi G, Kimura K, Sugawara T, et al. Percutaneous cholecystostomy versus gallbladder aspiration for acute cholecystitis: a prospective randomized controlled trial. AJR am J Roentgenol. 2004;183:193-6.

13. Chopra S, Dodd GD 3rd, Mumbower AL, Chintapalli KN, Schwesinger WH, Sirinek KR, et al. Treatment of acute cholecystitis in non-critically ill patients at high surgical risk: comparison of clinical outcomes after gallbladder aspiration and after percutaneous cholecystostomy. AJR am J Roentgenol. 2001;176:1025-31.

14. Davis CA, Landercasper J, Gundersen LH, Lambert PJ. Effective use of percutaneous cholecystostomy in high-risk surgical patients: techniques, tube management, and results. Arch Surg. 1999;134:727-31. discussion 731-722

15. Chikamori F, Kuniyoshi N, Shibuya S, Takase Y. Early scheduled laparoscopic cholecystectomy following percutaneous transhepatic gallbladder drainage for patients with acute cholecystitis. Surg Endosc. 2002;16:1704-7.

16. Kim HO, Ho Son B, Yoo CH, Ho Shin J. Impact of delayed laparoscopic cholecystectomy after percutaneous transhepatic gallbladder drainage for patients with complicated acute cholecystitis. Surg Laparosc Endosc Percutan Tech. 2009;19:20-4.

17. Yamada K, Yamashita Y, Yamada T, Takeno S, Noritomi T. Optimal timing for performing percutaneous transhepatic gallbladder drainage and subsequent cholecystectomy for better management of acute cholecystitis. J Hepatobiliary Pancreat Sci. 2015;22:855-61.

18. Asai K, Watanabe M, Kusachi S, Matsukiyo H, Saito T, Kodama H, et al. Risk factors for conversion of laparoscopic cholecystectomy to open surgery associated with the severity characteristics according to the Tokyo guidelines. Surg Today. 2014;44:2300-4.

19. Hutchinson CH, Traverso LW, Lee FT. Laparoscopic cholecystectomy. Do preoperative factors predict the need to convert to open? Surg Endosc. 1994:8:875-8. discussion 879-880

20. Sippey M, Grzybowski M, Manwaring ML, Kasten KR, Chapman WH, PofahI WE, et al. Acute cholecystitis: risk factors for conversion to an open procedure. J Surg res. 2015;199:357-61.

21. Bickel A, Hoffman RS, Loberant N, Weiss M, Eitan A. Timing of percutaneous cholecystostomy affects conversion rate of delayed laparoscopic cholecystectomy for severe acute cholecystitis. Surg Endosc. 2016;30:1028-33.

22. Brodsky A, Matter I, Sabo E, Cohen A, Abrahamson J, Eldar S. Laparoscopic cholecystectomy for acute cholecystitis: can the need for conversion and the probability of complications be predicted? A prospective study. Surg Endosc. 2000;14:755-60.

23. Hayama S, Ohtaka K, Shoji Y, Ichimura T, Fujita M, Senmaru N, et al. Risk factors for difficult laparoscopic cholecystectomy in acute cholecystitis. JSLS. 2016;20:e2016.00065.

24. Iwashita Y, Hibi T, Ohyama T, Honda G, Yoshida M, Miura F, et al. An opportunity in difficulty: Japan-Korea-Taiwan expert Delphi consensus on surgical difficulty during laparoscopic cholecystectomy. J Hepatobiliary Pancreat Sci. 2017;24(4):191-8.

25. Han IW, Jang JY, Kang MJ, Lee KB, Lee SE, Kim SW. Early versus delayed laparoscopic cholecystectomy after percutaneous transhepatic gallbladder drainage. J Hepatobiliary Pancreat Sci. 2012:19:187-93.
26. Vogelzang RL, Nemcek AA Jr. Percutaneous cholecystostomy: diagnostic and therapeutic efficacy. Radiology. 1988;168:29-34.

27. Patterson EJ, McLoughlin RF, Mathieson JR, Cooperberg PL, JK MF. An alternative approach to acute cholecystitis. Percutaneous cholecystostomy and interval laparoscopic cholecystectomy. Surg Endosc. 1996;10:1185-8.

28. Holmdahl L, Ivarsson ML. The role of cytokines, coagulation, and fibrinolysis in peritoneal tissue repair. Eur J Surg. 1999;165:1012-9.

29. Divilio LT. Surgical adhesion development and prevention. Int Surg. 2005:90:56-9.

\section{Submit your next manuscript to BioMed Central and we will help you at every step:}

- We accept pre-submission inquiries

- Our selector tool helps you to find the most relevant journal

- We provide round the clock customer support

- Convenient online submission

- Thorough peer review

- Inclusion in PubMed and all major indexing services

- Maximum visibility for your research

Submit your manuscript at www.biomedcentral.com/submit

) Biomed Central 